REVISTA EVIDENCIAÇÃO CONTÁBIL \& FINANÇAS

João Pessoa, v.6, n.2, p.58-80, mai./ago. 2017.

ISSN 2318-1001

DOI:10.18405/recfin20180204

Disponível em: http://periodicos.ufpb.br/ojs2/index.php/recfin

\title{
EVIDENCIAÇÃO DA INFORMAÇÃO CONTÁBIL: UMA RETROSPECTIVA DAS PESQUI- SAS SOCIALIZADAS NO CONGRESSO ANPCONT ${ }^{1}$
}

\author{
ACCOUNTING INFORMATION DISCLOSURE: A RETROSPECTIVE OF SOCIALIZED RE- \\ SEARCHES IN THE ANPCONT CONGRESS
}

\author{
Iago Franca Lopes ${ }^{2}$ \\ Doutorando em Ciências Contábeis pela Universidade Federal do Paraná \\ iagofrancalopes@gmail.com \\ https://orcid.org/0000-0001-7627-4815
}

\author{
Ilse Maria Beuren \\ Doutora em Controladoria e Contabilidade pela Universidade de São Paulo \\ Professora do Programa de Pós-Graduação em Ciências Contábeis da Universidade Federal do Paraná \\ ilse.beuren@gmail.com \\ https://orcid.org/0000-0003-4007-6408
}

\begin{abstract}
RESUMO
Objetivo: Este estudo objetiva analisar as características das pesquisas sobre evidenciação contábil socializadas no Congresso ANPCONT no período de 2007 a 2016.

Fundamento: A evidenciação contábil é uma das formas visadas de comunicação com os agentes de mercado. Nesse cenário, a pesquisa contábil enquanto prática de ordem social e institucional instiga desenvolver estudos que contribuam para uma maior confiabilidade nas informações divulgadas pelas empresas.
\end{abstract}

Método: $\mathrm{O}$ processo de seleção dos trabalhos ocorreu em etapas sistemáticas e resultou em uma amostra de 90 trabalhos. Neles investigaram-se aspectos temporais, autoria, temática, enfoque teórico e metodológico, foco em informações obrigatórias ou voluntárias e uso da escala dicotômica para determinar o nível de evidenciação.

Resultados: Os resultados evidenciam uma evolução temporal dos estudos sobre evidenciação contábil, e duas universidades se destacaram pelos pesquisadores com maior número de trabalhos apresentados neste evento. As teorias de base que prevaleceram são Teoria da Divulgação e Teoria da Agência. As temáticas mais destacadas são a evidenciação ambiental e social e a evidenciação das informações presentes nas demonstrações contábeis, com ênfase em atos regulatórios e normativos. Os procedimentos metodológicos mais utilizados circunscreveram-se à análise de conteúdo com uso de ferramentas estatísticas.

Contribuições: Os achados evidenciam vieses de pesquisas sobre evidenciação contábil, além de

\footnotetext{
1 Artigo recebido em: 13/09/2018. Revisado por pares em: 23/10/2017. Reformulado em: 15/02/2018. Recomendado para publicação em: 21/02/2018 por Luiz Felipe de Araújo Pontes Girão (Editor Geral). Publicado em: 07/03/2018. Organização responsável pelo periódico: UFPB.

2 Endereço: Rua XV de Novembro, 1299 - Centro, Curitiba - PR, 80060-000

DOI: http://dx.doi.org/10.18405/recfin20180204

Os autores agradecem à Coordenação de Aperfeiçoamento de Pessoal de Nível Superior pelo apoio financeiro.
} 
fornecer insights sobre os mesmos. Reforçam, ainda, o papel que as universidades vêm desempenhando na geração de conhecimento e na busca por caminhos alternativos que demonstrem a relevância do acionista para o desenvolvimento organizacional, face à influência do normatizador nas temáticas investigadas.

Palavras-chaves: Evidenciação da informação contábil. Pesquisas socializadas. Congresso ANPCONT.

\section{ABSTRACT}

Objective: The goal of this study is to analyze the characteristics of research of the accounting disclosure socialized in the ANPCONT Congress in the period from 2007 to 2016.

Background: The accounting disclosure is one of the targeted forms of communication with market agents. In this scenario, the accounting research as a practice of social and institutional order instigates to develop studies that contribute to a greater reliability in the information disclosed by the companies.

Method: The papers selection process was conducted in systematic steps and resulted in a sample of 90 works. In them, temporal aspects, authorship, themes, theoretical and methodological approach, scope, focus on mandatory or voluntary information and use of the dichotomous scale to determine the level of evidence were investigated.

Results: The results show a temporal evolution of the studies on accounting disclosure, and two universities stood out for having researchers with the highest number of papers presented at this event. The basic theories that prevailed are the Disclosure Theory and the Agency Theory. The most outstanding themes are the environmental and social disclosure and the disclosure of information present in the financial statements, with an emphasis on regulatory and normative acts. The most commonly used methodological procedures circumscribed the content analysis with the use of statistical tools.

Contributions: The findings show biases in research on accounting disclosure, as well as providing insights about them. They also reinforce the role that universities have played in the generation of knowledge and in the search for alternative ways to demonstrate the relevance of the shareholder for organizational development, given the influence in the investigated themes.

Keywords: Accounting Information Disclosure; Socialized Researches; ANPCONT Congress.

\section{INTRODUÇÃO}

A pesquisa contábil é uma prática que contribui para o desenvolvimento das instituições e da sociedade, visto que existe uma conexão entre a contabilidade e o contexto social. À luz dessa perspectiva e em resposta a fracassos de empresas, as quais aos olhos do mercado eram consideradas economicamente rentáveis e promissoras, ou a escândalos de corrupção de dirigentes de empresas, a evidenciação contábil ampliou sua relevância como um mecanismo de comunicação utilizado pelos agentes de mercado.

Esse cenário instiga o meio acadêmico a desenvolver estudos de visão interativa, que ampliem a percepção das partes interessadas sobre a necessidade de criação de mecanismos que contribuam para maior confiabilidade nas informações divulgadas pelas empresas. Essa motivação ultrapassa aspectos relacionados à tomada de decisão dos stakeholders. Perpassa a necessidade de transparência visto que a informação tem valor preditivo na condução dos mercados de capitais (Fama, 1970; Macedo, Almeida, \& Dornelles, 2016).

De acordo com Barboza, Sousa, Nascimento, Bernardes e Castro (2015), a pesquisa contábil brasileira tem incentivado o desenvolvimento da pluralidade de temáticas, além de sua socialização em eventos científicos e publicação em periódicos da área. Enseja-se que o conhecimento construído no âmbito acadêmico seja acessível à sociedade e às instituições, de modo a desenvolver um diálogo 
contínuo entre ambos, especialmente com a participação em eventos científicos com esse enfoque.

Neste sentido, em 30 de janeiro de 2006 foi fundada a Associação Nacional de Programas de Pós-Graduação em Ciências Contábeis (ANPCONT), com o objetivo de congregar e representar as instituições brasileiras que mantêm cursos de mestrado e/ou doutorado em Ciências Contábeis. Esta associação, desde 2007 promove o Congresso ANPCONT, que "proporciona a interação da comunidade acadêmica, pesquisadores, professores e estudantes, representando um meio de divulgação da produção técnico-científica na área das Ciências Contábeis" (ANPCONT, 2017, p. 01).

As pesquisas sobre evidenciação contábil abrangem uma diversidade teórica para explicar o comportamento dos agentes econômicos, além de buscar "entender os fatores que motivam a criação das normas que tornem a evidenciação obrigatória ou que levam às divulgações voluntárias" (Suzart, 2016, p. 67). Nesse contexto, este estudo objetiva analisar as características das pesquisas sobre evidenciação contábil socializadas no Congresso da ANPCONT no período de 2007 a 2016.

O Congresso da ANPCONT foi selecionado pela sua função legitimadora enquanto representante civil dos cursos stricto sensu em Contabilidade, no país, sendo 2.058 de mestrado acadêmico, 530 de mestrado profissional e 451 de doutorado (Bernd, Anzilago, \& Beuren, 2017, p. 408). Além disso, destaca-se sua ênfase contábil, em específico nas seguintes áreas temáticas: Contabilidade para Usuários Externos, Controladoria e Contabilidade Gerencial, Educação e Pesquisa em Contabilidade, Mercados Financeiro, de Crédito e de Capitais e Contabilidade Aplicada ao Setor Público e ao Terceiro Setor.

A relevância do estudo está em discutir o perfil das pesquisas sobre evidenciação contábil no Brasil socializadas no Congresso ANPCONT. Destaca-se em especial o fato de revelar tendências enquanto temática de pesquisa, teorias mais utilizadas e temáticas em voga no ambiente acadêmico. Cardoso, Pereira e Guerreiro (2007) sinalizam que pesquisas desta natureza, que buscam apresentar aparatos qualitativos e quantitativos de um campo de pesquisa, estão ligadas a duas vertentes no meio acadêmico: ao desenvolvimento da carreira do docente; e à ascensão dos programas de pósgraduação.

Pesquisas empíricas socializadas no Congresso ANPCONT já foram foco de Ribeiro (2017), que fez um levantamento do perfil das pesquisas da área temática de mercado financeiro, de crédito e de capitais. Também foi de interesse de Cosenza, Paula, Laurencel e Barreto (2016) que analisaram o diálogo entre as pesquisas da área de contabilidade gerencial e contabilidade financeira. De Ribeiro, Camacho, Moraes e Raimundini (2015), que analisaram a cientificidade e metodologias dos trabalhos de contabilidade gerencial socializados no evento. De Amaral, Santana, Sales e Araujo Neto (2014), que avaliaram o perfil dos autores com trabalhos socializados nos congressos USP e ANPCOT.

Ainda em relação aos trabalhos teóricos-empíricos socializados no Congresso ANPCONT, o processo de construção do conhecimento sobre o ensino e a aprendizagem em Contabilidade foi investigado por Santos, Pires, Macambira e Bruni (2013). A diversidade inovadora e o isomorfismo foram foco da pesquisa de Paula, Silva, Vieira e Coutinho (2012). Uma análise bibliométria avaliativa e descritiva do período de 2007 a 2011 foi o alvo de Matos, Niyama, Araujo Neto e Marques (2012). Aspectos metodológicos das pesquisas e perfil dos congressistas foram enfatizados por Dallabona et al. (2011). A participação feminina nas pesquisas foi foco de Luca, Gomes, Corrêa e Domingos (2011).

Assim, o estudo alinha-se à proposição de Van Der Stede (2015) ao buscar contribuir com a pesquisa para a prática e não a pesquisa para a pesquisa, como uma entrada para o diálogo junto às organizações. Este estudo pretende gerar insights à reflexão sobre a direção da produção científica em contabilidade, no que concerne à temática evidenciação contábil. A escolha da temática é relevante para a área contábil, uma vez que está fortemente relacionada com a função da contabilidade, a qual tem "permanecido inalterada desde seus primórdios e sua finalidade é prover os usuários 
dos demonstrativos financeiros com informações que os ajudarão a tomar decisões" (Iudícibus, 2000, p. 18). Além disso, a evidenciação contábil é um condutor chave do funcionamento dos mercados de capitais, pois existe uma relação clara entre a informação divulgada e o comportamento do acionista.

\section{REFERENCIAL TEÓRICO}

\subsection{Evidenciação Contábil}

A evidenciação contábil é um campo de pesquisa que abrange as áreas de contabilidade, finanças e economia, portanto, incorpora em sua prática características dessas áreas (Verrecchia, 2001). Para Suzart (2016), a evidenciação tem por finalidade divulgar informações de uma entidade a respeito da composição do seu patrimônio e dos fluxos financeiros de suas atividades e as decisões dos gestores tomadas durante um exercício. Neste estudo, os termos evidenciação, disclosure e divulgação são usados como sinônimos.

A abrangência da contabilidade lhe confere prerrogativas, ao mesmo tempo que lhe exige atenção para especificidades, como é o caso de questões relacionadas a evidenciação no processo decisório e na mitigação da assimetria informacional. A quem deve ser divulgada a informação? Qual a sua finalidade? E quanta informação deve ser divulgada? (Hendriksen \& Van Breda, 1999). Ainda, a evidenciação pode ser de informações obrigatórias ou voluntárias, mas a essência é a mesma, a de servir os usuários da informação contábil.

Hendriksen e Van Breda (1999) aduzem que a divulgação apropriada se baseia no aumento do bem-estar social, o que dificulta ainda mais o alcance de um nível de evidenciação que atinja e/ou contemple todos os usuários. O entendimento que prevalece é que os usuários precisam tomar decisões com base no que é divulgado pelas empresas, portanto, é preciso que as informações sejam disponibilizadas de forma geral e não isolada, mesmo que não venham a contemplar todas as necessidades dos usuários.

O pressuposto da evidenciação é segregar as informações em duas categorias: (i) informações obrigatórias, que correspondem ao "conjunto mínimo de informações contábeis que uma entidade deve divulgar compulsoriamente, para não sofrer sanções por parte dos órgãos reguladores" (Suzart, 2016, p. 54); e (ii) informações voluntárias, que compreendem "o conjunto de informações contábeis que é divulgado livremente por uma entidade, sem que haja uma norma que lhe obrigue a realizar tal divulgação" (Suzart, 2016, p. 54).

As informações obrigatórias são divulgadas em conformidade com a legislação vigente. No caso do Brasil, com a promulgação da Lei n⿳ำ 11.638/2007 e legislações decorrentes, o País passou por um processo de convergência às normas internacionais de contabilidade, o que se refletiu na qualidade da evidenciação exigida das empresas. Já as informações voluntárias caracterizam-se por não apresentarem caráter normativo, e são disponibilizadas por meio de canais formais e informais (Gibbins, Richardson, \& Waterhouse, 1990, Lanzana, 2004).

As informações involuntárias também preocupam a pauta dos compromissos corporativos. Para Skillius e Wennberg (1998), o disclosure involuntário tangencia a comunicação de informações, principalmente por canais informais, e remete à ação ambiental de uma organização sem a sua permissão ou contra sua vontade. Nesta perspectiva, Mendes (2013) investigou se este modo de disclosure, quando ocorrido de forma negativa decorrente de acidentes ambientais, possui capacidade de alterar a volatilidade das ações. Os achados indicaram que "a volatilidade das ações não difere significantemente, antes e depois do acidente ambiental" (Mendes, 2013, p. 10).

A evidenciação involuntária tangencia dois aparatos teóricos. O primeiro refere-se à assimetria informacional, ou seja, "alguns agentes econômicos têm mais informações do que outros" (Belo \& Brasil, 2006, p. 50). O segundo versa sobre a eficiência do mercado, sua ênfase paira sobre a "velocidade do ajuste dos preços a partir de informações públicas disponíveis" (Maciel, Wolff, \& Rêgo, 
2016, p. 02). Assim, pesquisas que identifiquem as características de estudos sobre evidenciação contábil têm a capacidade de apresentar uma lacuna na construção de novos conhecimentos.

Nesse sentido, Mattos (2004, p. 2) assevera que a análise bibliométrica é "usada como estratégia estruturadora da pesquisa e não apenas como técnica auxiliar de análise de uma pesquisa já conceitualmente estruturada e fundamentada [...] que eles mesmos construíram de determinada maneira". Paula et al. (2012) destacam que pesquisas dessa natureza apresentam preocupações relativamente comuns no que concerne à pesquisa, como: temas, abordagens metodológicas, paradigmas, instituições e autores com maior quantidade de publicações e citações e tipos de referências bibliográficas, entre outros.

Alinhado com esta perspectiva, Suzart (2016) relacionou em sua pesquisa as principais visões teóricas que tentam explicar o fenômeno da evidenciação de informações contábeis. Todavia, seu foco principal foi realizar uma reflexão sobre a "intensidade com que a prática de soma de itens em uma escala dicotômica enviesa a classificação das entidades com vistas na redução de variáveis qualitativas" (Suzart, 2016, p. 53) em pesquisas contábeis.

\subsection{Estudos sobre evidenciação contábil}

No intuito de explorar e sustentar os resultados deste estudo, elencam-se a seguir pesquisas bibliométricas que analisaram características das publicações envolvendo a temática evidenciação contábil. Desse modo, pode-se avaliar se os trabalhos socializadas no Congresso ANPCONT se relacionam com pesquisas anteriores publicadas em periódicos.

Carvalho e Ensslin (2006) desenvolveram um estudo que identificou o estado da arte da pesquisa sobre evidenciação do Capital Intelectual (CI), considerando o período de 2000 a 2005. Constaram que há um predomínio em investigar até 20 empresas, por meio de relatórios anuais e, principalmente, por meio de análise de conteúdo, características fortemente presentes nos estudos de evidenciação.

Rosa, Ensslin e Ensslin (2009) mapearam os artigos sobre avaliação da evidenciação ambiental. a partir de um processo estruturado de busca. Os resultados evidenciados contribuem para a presente discussão no que concerne à categorização das informações ambientais divulgadas pelas empresas. As análises categóricas observadas revelaram-se divergentes entre as pesquisas, por exemplo, quanto a forma de categorizar a evidenciação ambiental e de critérios de identificação da evidenciação ambiental (Rosa et al., 2009). Isso reforça a existência de subjetividade na composição destas métricas de evidenciação.

Murcia, Santos, Salotti e Nascimento (2010) mapearam a literatura internacional sobre disclosure ambiental no período de 1997 a 2007. De acordo com os resultados da investigação, não foram identificadas pesquisas realizadas no Brasil. Outra constatação foi que "pesquisas com usuários dessas informações sugerem a necessidade de padronização para melhorar a comparabilidade entre empresas (Murcia et al., 2010, p. 16). De modo complementar, ainda apontaram os autores mais prolíficos na área e as fontes de coleta de dados.

Rosa, Ensslin, Ensslin e Lunkes (2011) buscaram identificar as oportunidades de pesquisa no campo da evidenciação contábil. Para tal, analisaram 11 artigos e encontraram algumas evidências que se destacaram neste campo de pesquisa. Primeiro, a análise de conteúdo é a técnica que predominou neste campo de pesquisa. O estudo ainda destacou a necessidade de desenvolver escalas para a mensuração dos critérios de evidenciação contábil, os quais deseja-se identificar via análise de conteúdo.

Ferreira e Martins (2016) realizaram uma análise bibliométrica de 42 artigos sobre a mensuração do disclosure nos principais periódicos internacionais da área de finanças. O recorte temporal compreendeu desde as primeiras publicações de cada periódico até meados de setembro de 2014. Os resultados que podem contribuir para a presente discussão são os que incidem sobre as temáticas 
investigadas, concentrados em regulamentação (42,9\%), assimetria informacional (33,3\%) e value relevância 23,8\%). Essa contribuição decorre do cenário normativo vivenciado pelas empresas brasileiras, o que por vezes incentiva o volume de pesquisas sobre evidenciação no âmbito nacional sobre estas temáticas.

Manzi e Pimentel (2016) concentraram sua revisão de literatura no disclosure ambiental. Analisaram 60 artigos distribuídos em 12 periódicos disponíveis no Portal de Periódicos da Coordenação de Aperfeiçoamento de Pessoal de Nível Superior (CAPES), no período de 2005 a 2015. A revisão da literatura evidenciou que no ano de 2013 os periódicos publicaram o maior número de artigos sobre a temática. Constataram ainda um predomínio de pesquisas descritivas, com abordagem quantitativa, realizadas a partir de documentos.

Evidências da perpetuação de pesquisas sobre a evidenciação contábil são observadas nesta seção. No entanto, não se constatou a investigação de trabalhos socializados no Congresso ANPCONT como campo de pesquisa para mapear a temática evidenciação contábil. Tal fato oportuniza esta investigação, que busca contribuir para o desenvolvimento desse campo científico e de futuras pesquisas nesta área do conhecimento.

\section{METODOLOGIA DA PESQUISA}

Para esta pesquisa bibliométrica selecionaram-se os trabalhos sobre evidenciação contábil socializados no Congresso da ANPCONT, contidos nos anais das edições do evento do período de 2007 a 2016. A abordagem do problema caracteriza-se como sendo de natureza mista, pois recaiu na abordagem qualitativa e quantitativa.

Para o processo de seleção dos trabalhos, inicialmente fez-se um levantamento dos anais do Congresso ANPCONT do período de 2007 a 2016. Após, definiu-se o campo de abrangência, no caso, evidenciação contábil. Na sequência, realizou-se uma busca nos anais com as palavras-chave "evidenciação", "divulgação" e "disclosure" no título dos trabalhos, resumos e palavras-chave, o que resultou em 105 trabalhos. Em seguida, procedeu-se à leitura dos resumos, para averiguar seu alinhamento com a temática estabelecida, momento em que foram excluídos 15 trabalhos.

Após a definição da amostra do estudo, composta de 90 trabalhos, procedeu-se à leitura do referencial teórico e dos procedimentos metodológicos adotados nestes estudos. Paralelamente, foi elaborado um banco de dados, com o uso do software Microsoft Office Excel ${ }^{\circledR}$, a partir dos dados levantados nessas leituras (ano, autores, universidade, área temática do Congresso, ambiente de abrangência da pesquisa, teorias adotadas, metodologia da pesquisa, tipo de informação investigada (divulgação obrigatória ou voluntária) e uso de escala dicotômica.

$\mathrm{Na}$ análise da autoria dos trabalhos, fez-se uso da Lei de Lotka ou Lei do Quadrado Inverso. Essa, segundo Vanti (2002, p. 153), “[...] aponta para a medição da produtividade dos autores, mediante um modelo de distribuição tamanho-frequência dos diversos autores em um conjunto de documentos". A expressão matemática que elucida a operacionalização da Lei é apresentada na Equação 1:

$$
\alpha_{n}=\alpha_{1} \times \frac{1}{n^{c}}
$$

Onde:

$\alpha_{n}=$ número de autores com $\mathrm{n}$ artigos

$\alpha_{1}=$ número de autores que publicaram apenas um artigo

$n=$ número de artigos

$c=$ coeficiente de Lotka $(\approx 2)$

Nesta pesquisa investigou-se o número de autores com até nove trabalhos, que corresponde ao número máximo de autores com pesquisas socializadas no Congresso no período. Para analisar os dados utilizou-se estatística descritiva, cujo objetivo básico é o de "sintetizar uma série de valores 
de mesma natureza, permitindo dessa forma que se tenha uma visão global da variação desses valores" (Guedes, Martins, Acorsi, \& Janeiro, p. 1, 2015).

\section{DESCRIÇÃO E ANÁLISE DOS RESULTADOS}

Na Tabela 1, apresenta-se a proporção de trabalhos sobre evidenciação socializada no Congresso ANPCONT no período de 2007 a 2016. Ao longo dos 10 anos ocorreu um aumento do número de trabalhos socializados no Congresso. No entanto, o volume de trabalhos sobre evidenciação contábil não apresentou comportamento assimétrico com o número total de trabalhos socializados nas diversas edições do Congresso. Ademais, nota-se um declínio de trabalhos sobre evidenciação contábil nos anos de 2013 e 2016.

Tabela 1 - Evolução temporal dos trabalhos sobre evidenciação contábil no Congresso ANPCONT

\begin{tabular}{ccccc}
\hline Ano & $\begin{array}{c}\text { Total de trabalhos do Con- } \\
\text { gresso ANPCONT }\end{array}$ & $\begin{array}{c}\text { Total de trabalhos sobre Evi- } \\
\text { denciação Contábil }\end{array}$ & Prop. (\%) & Freq. (\%) \\
\hline 2007 & 49 & 3 & 6 & 3 \\
2008 & 48 & 4 & 8 & 4 \\
2009 & 107 & 5 & 4 & 6 \\
2010 & $\mathbf{8 0}$ & $\mathbf{9}$ & $\mathbf{1 1}$ & $\mathbf{1 0}$ \\
$\mathbf{2 0 1 1}$ & $\mathbf{9 5}$ & $\mathbf{1 3}$ & $\mathbf{1 3}$ & $\mathbf{1 1}$ \\
$\mathbf{2 0 1 2}$ & $\mathbf{9 6}$ & $\mathbf{1 1}$ & 7 & $\mathbf{1 2}$ \\
2013 & 96 & $\mathbf{1 3}$ & $\mathbf{1 3}$ & $\mathbf{1 3}$ \\
$\mathbf{2 0 1 4}$ & $\mathbf{1 0 0}$ & $\mathbf{1 6}$ & $\mathbf{1 3}$ & $\mathbf{1 4}$ \\
$\mathbf{2 0 1 5}$ & $\mathbf{1 1 8}$ & 9 & 6 & $\mathbf{1 3}$ \\
2016 & 141 & $\mathbf{9 0}$ & $\mathbf{4}$ & 10 \\
\hline Total & $\mathbf{9 3 0}$ & & & $\mathbf{1 0 0}$ \\
\hline
\end{tabular}

Fonte: elaboração própria.

Todos os anos analisados tiveram trabalhos sobre evidenciação, mas destacaram-se os anos de 2011 (13 trabalhos), 2012 (11 trabalhos), 2014 (13 trabalhos) e 2015 (16 trabalhos), representando aproximadamente $71,58 \%$ do total dos trabalhos sobre evidenciação contábil. Alguns fatores podem ter contribuído para este cenário, como o aumento da preocupação com a reputação corporativa, uma vez que a evidenciação é uma das formas para os gestores comunicarem aos usuários da informação contábil o desempenho da empresa, suas perspectivas futuras quanto a continuidade dos negócios, suas ações econômicas, sociais e ambientais, e legitimar o contrato entre a sociedade e a organização.

Além disso, no período de 10 anos, pode-se constatar que o volume de trabalhos sobre evidenciação no Congresso alinhou-se com momentos em que a contabilidade apresentava-se imersa em mudanças. Por exemplo, no ano de 2008, o Brasil passou a adotar as Normas Internacionais de Contabilidade (International Financial Reporting Standards - IFRS), a partir da promulgação da Lei ${ }^{\circ}$ 11.638, de 28 de dezembro de 2007. Consequentemente, nos anos seguintes, principalmente de 2010 a 2012, observa-se a presença de pesquisas sobre evidenciação com caráter diagnóstico.

Este período de transição, da adoção das IFRS frente às Normas Brasileiras de Contabilidade, causou certo desconforto aos usuários da contabilidade, uma vez que as informações anteriormente repassadas poderiam estar momentaneamente sendo geradas de modo diferente. É nesse sentido que os estudos sobre evidenciação podem contribuir, visto que tal cenário demanda maior atenção dos usuários da contabilidade na tomada de decisão e também em relação às informações disponibilizadas.

Nos anos de 2014 e 2015 o caráter explicativo foi dominante entre as investigações analisadas. Tal cenário pode ter resultado de eventos econômico-financeiros vivenciados pelas organizações, como a crise do país. Esse período foi marcado por recessão, onde o PIB apresentou um crescimento médio negativo de 3,7\%. Por outro lado, as organizações foram obrigadas a se reinventar, à medida 
que eram expostas à políticas intervencionistas. Esses elementos são passíveis de estímulo à pesquisas sobre evidenciação contábil, visto que o cenário das organizações estava imerso em insegurança política e econômica (Formiga, Barros, Cezário, \& Scherer, 2017; Paula \& Pires, 2017).

No escopo autoria dos trabalhos, observou-se predominância de coautoria entre 3 autores, em 30 dos 90 trabalhos analisados. Os demais estão segregados em parcerias com 2 autores (28,89\%), 4 autores (32,22\%). Apenas 5 trabalhos (5,56\%) foram desenvolvidos de forma individual. Não encontraram-se trabalhos com mais de 4 autores na amostra analisada, o que é um requisito do congresso, os trabalhos devem possuir no máximo quatro autores (ANPCONT, 2017). Na Tabela 2 mostra-se a produtividade dos autores dos trabalhos sobre evidenciação contábil socializados no Congresso ANPCONT conforme o padrão Lotka.

Tabela 2 - Total de trabalhos por autor socializados no Congresso ANPACONT sobre Evidenciação Contábil (2007-2016)

\begin{tabular}{c|c|c|c}
\hline $\begin{array}{c}\text { No de trabalhos por } \\
\text { autor }\end{array}$ & Padrão Lotka (\%) & $\begin{array}{c}\text { No de trabalhos por autor no } \\
\text { Congresso ANPCONT }\end{array}$ & $\begin{array}{c}\text { \% de trabalhos por autor no } \\
\text { Congresso ANPCONT }\end{array}$ \\
\hline 1 & 60,80 & 162 & 62 \\
2 & 15,20 & 46 & 17 \\
3 & 6,76 & 21 & 2 \\
4 & 3,80 & 4 & 4 \\
5 & 2,43 & 10 & 5 \\
6 & 1,69 & 12 & 0 \\
7 & 1,24 & 0 & 3 \\
8 & 0,95 & 8 & $\mathbf{1 0 0 \%}$ \\
\hline Total & - & $\mathbf{2 6 3}$ &
\end{tabular}

Observa-se na Tabela 2 que a quantidade de autores que socializaram apenas um trabalho sobre evidenciação contábil no Congresso ANPCONT, no período analisado, está próxima do parâmetro estabelecido pela Lei de Lotka. Ou seja, $62 \%$ dos autores socializaram no Congresso apenas um trabalho sobre evidenciação contábil no período analisado, enquanto que 3\% dos autores socializaram 8 trabalhos. Foi identificado na amostra um total de 198 autores que tiveram seu nome vinculado aos trabalhos socializados no Congresso ANPCONT. Ressalta-se que, em algumas situações, um mesmo autor teve envolvimento com mais de um trabalho no período analisado, o que resultou em um total de 263 trabalhos socializadas. Nesse escopo, os resultados desta pesquisa estão de acordo com os estabelecidos pela Lei de Lotka.

Quanto à autoria dos trabalhos e ao Padrão Lotka, pode-se inferir que há interesse pela temática evidenciação contábil. Pode-se, com parcimônia, inferir que existe um campo de pesquisa consolidado nesta área de conhecimento. Algumas inferências permeiam as pesquisas, como, por exemplo: empresas maiores possuem maior nível de evidenciação (Lima, Costa, Pinheiro, \& Lamounier, 2016); quanto maior o índice de liquidez maior o nível de evidenciação (Araújo, Machado, \& Machado, 2016); os elementos de governança corporativa influenciam no nível de evidenciação das empresas (Macedo, Oliveira, Nobre, Brito, \& Quandt, 2015); entre outras já consolidadas na área.

Na Tabela 3 apresenta-se o vínculo institucional dos autores dos trabalhos sobre evidenciação contábil socializados no Congresso ANPCONT. Optou-se por analisar o vínculo institucional dos autores por trabalho, o que ocasionou em duplicação de autores e, nesta condição, resultou em 263 vínculos institucionais. 
Tabela 3 - Vínculo institucional e quantidade de autores por instituição identificados nos trabalhos socializados no Congresso ANPCONT

\begin{tabular}{l} 
Instituição \\
\hline UnB - Universidade de Brasília \\
UFG - Universidade Federal de Goiás \\
UNIEURO - Centro Universitário Unieuro \\
UNEMAT - Universidade do Estado de Mato Grosso \\
UEMS - Universidade Estadual de Mato Grosso do Sul \\
CGU - Controladoria Geral da União \\
STN - Secretaria do Tesouro Nacional \\
UFRGS - Universidade Federal do Rio Grande do Sul
\end{tabular}

\begin{tabular}{cccc} 
Programa & Região & Quant & Freq. $\%$ \\
\hline Ciências Contábeis & & 6 & 2,28 \\
Ciências Contábeis & & 3 & 1,14 \\
- & & 1 & 0,38 \\
Ciências Contábeis & Centro- & 1 & 0,38 \\
- & Oeste & 1 & 0,38 \\
- & & 1 & 0,38 \\
- & & 1 & 0,38
\end{tabular}

UFC - Universidade Federal do Ceará

UFBA - Universidade Federal da Bahia

UFPB - Universidade Federal da Paraíba

UNIFOR - Universidade de Fortaleza

UFPE - Universidade Federal de Pernambuco

UnB/UFPB/UFPE/UFRN - Programa MultiInstitucional e InterRegional em Ciências Contábeis

UEPB - Universidade Estadual da Paraíba

UFERSA - Universidade Federal Rural do SemiÁrido

UNEB - Universidade do Estado da Bahia

dade

$1 \quad 0,38$

Administração e Controlado-

ria

14,83

Contabilidade

Ciências Contábeis

Administração de Empresa $\quad 6 \quad 2,28$

$\begin{array}{llr}\text { Ciências Contábeis } & 5 & 1,90\end{array}$

Ciências Contábeis $\quad$ Nordeste $\quad 4 \quad 1,52$

Administração Pública

UERN - Universidade do Estado do Rio Grande do

Norte

UFPI - Universidade Federal do Piauí

FURG - Universidade Federal do Rio Grande

UFRN - Universidade Federal do Rio Grande do Norte

USP - Universidade de São Paulo

UFRJ - Universidade Federal do Rio de Janeiro

UFMG - Universidade Federal de Minas Gerais

FUCAPE - Fundação Instituto Capixaba de Pesquisa

em Contabilidade, Economia e Finanças

UFES - Universidade Federal do Espírito Santo

UPM - Universidade Presbiteriana Mackenzie

FECAP - Centro Universitário Álvares Penteado

FGV - Fundação Getúlio Vargas

USP/RP - Universidade de São Paulo Ribeirão Preto UERJ - Universidade do Estado do Rio de Janeiro UFU - Universidade Federal de Uberlândia

CCIMAR - Centro de Controle Interno da Marinha do

Brasil

UFSC - Universidade Federal de Santa Catariana

UNISINOS - Universidade do Vale do Rio dos Sinos

FURB - Universidade Regional de Blumenau

UFPR - Universidade Federal do Paraná

UEM - Universidade Estadual de Maringá

UDESC - Universidade do Estado de Santa Catarina

UNOESC - Universidade do Oeste de Santa Catarina

UEPG - Universidade Estadual de Ponta Grossa

SEFSC - Secretaria de Estado da Fazenda de Santa Catarina

URCAMP - Urcamp Livramento

\begin{tabular}{ccc} 
Administração Pública & 4 & 1,52 \\
- & 3 & 1,14 \\
- & & \\
- & 1 & 0,38 \\
Contabilidade & 1 & 0,38 \\
Ciências Contábeis & 1 & 0,38 \\
& 1 & 0,38 \\
\hline
\end{tabular}

Controladoria e Contabili-

dade

Ciências Contábeis

Ciências Contábeis

$\begin{array}{lll} & 32 & 12,17 \\ & 16 & 6,08 \\ & 12 & 4,56 \\ & & \\ \text { Sudeste } & 8 & 3,04 \\ & 7 & 2,66 \\ & 2 & 1,14 \\ & 2 & 0,76 \\ & & \\ & 2 & 0,76 \\ & 2 & 0,76 \\ 2 & 0,76\end{array}$

Ciências Contábeis

Ciências Contábeis

Ciências Contábeis

Ciências Contábeis

Administração

Controladoria e contabilidade

Ciências Contábeis

Ciências Contábeis

0,76
0,76

$\begin{array}{lll}- & 1 & 0,38\end{array}$

Contabilidade

Ciências Contábeis

Ciências Contábeis

Contabilidade

Ciências Contábeis

Administração

Administração

\begin{tabular}{ccc} 
& 18 & 6,84 \\
& 11 & 4,18 \\
& 10 & 3,80 \\
& 7 & 2,66 \\
Sul & 7 & 2,66 \\
& 2 & 0,76 \\
& 1 & 0,38 \\
& 1 & 0,38 \\
& & \\
& 2 & 0,76 \\
& 1 & 0,38 \\
\hline
\end{tabular}

Economia, Contabilidade e

Administração

Espanha

3

1,14




\begin{tabular}{lcccc}
\hline UC - Faculdade de Economia da Universidade de & & Portugal & & \\
Coimbra & Gestão & Tunísia & 2 & 0,76 \\
\hline ISCAE - Finance-Tunisia & Finanças & & $\mathbf{2 6 3}$ & $\mathbf{1 0 0}$ \\
\hline Total & & & \\
\hline
\end{tabular}

Fonte: elaboração própria.

Nota-se na Tabela 3 que os trabalhos apresentados no Congresso ANPCONT sobre a temática evidenciação contábil advém de 47 instituições, das quais 39 são universidades brasileiras. A universidade que mais se destacou no período foi a UFC (14,83\%). Esse destaque pode decorrer do Programa de Pós-Graduação em Administração e Controladoria apresentar linhas de pesquisa que denotam preocupação com o usuário externo, relacionadas à governança corporativa, qualidade informacional e meio ambiente. Outra universidade que se destacou foi a USP, com autoria de 32 trabalhos (12,17\%), que possui o Programa mais antigo e consolidado da área contábil. Destaca-se ainda que vários autores vinculados à órgãos de governo socializaram trabalhos sobre esta temática no Congresso.

No que concerne aos 263 vínculos institucionais computados e suas respectivas regiões do território brasileiro, nota-se que 92 deles concentram-se no Nordeste, 89 no Sudeste, 59 no Sul e 15 no Centro-Oeste. Na Tabela 4 destacam-se os autores que tiveram mais que dois trabalhos sobre a temática no Congresso ANPCONT no período analisado.

Tabela 4 - Autores com maior volume de trabalhos sobre evidenciação contábil socializados no Congresso ANPCONT

\begin{tabular}{l|c|c|c}
\hline Autor & Titulação & Vinculo Institucional & No de trabalhos \\
\hline MURCIA, F. D. R. & Doutorado & USP & 8 \\
SANTOS, A. & Doutorado & USP & 6 \\
PONTE, V. M. R. & UFC & 5 \\
OLIVEIRA, M. C. & Doutorado & UFC & 5 \\
BORTOLON, P. M. & Doutorado & UFES & 4 \\
PFITSCHER, E. D. & Uoutorado & UFSC & 3 \\
RODRIGUES, A. & Doutorado & UFBA & 3 \\
DIAS FILHO, J. M. & Doutorado & TCEC & 3 \\
MENESES, A. F. & Mestrado & UFSC & 3 \\
ROSA, F. S. & Doutorado & USP/RP & 3 \\
RIBEIRO, M.S. & Doutorado & TCEC & 3 \\
MAPURUNGA, P. V. R. & Mestrado & UFSC & 3 \\
ROVER, S. & Doutorado & - & 208 \\
OUTROS & - & & \\
\hline
\end{tabular}

Fonte: elaboração própria.

Verifica-se na Tabela 4 que o autor Murcia, F.D.R. socializou 8 trabalhos, enquanto Santos, A. e Ponte, V.M.R. 6 trabalhos cada um. Já Oliveria, M.C.E e Bortolon, P.M. socializaram 5 trabalhos e Pfitscher, E.D. 4 trabalhos. Os autores com 3 trabalhos no período analisado são: Rodrigues, A., Dias Filho, J.M., Meneses, A.F., Rosa, F.S., Ribeiro, M.S., Mapurunga, P.V.R. e Rover, S. Os demais autores, um total de 55, isto é, 263 - 208, socializaram dois ou apenas um trabalho no período analisado.

Dentre os 13 autores com mais trabalhos, três indicaram vínculo institucional com a Universidade de São Paulo, dois com a Universidade Federal do Ceará, dois com a Universidade Federal de Santa Catarina, dois com o Tribunal de Contas do Estado do Ceará, um com a Universidade Federal do Rio de Janeiro, um com a Universidade Federal do Espírito Santo e um com a Universidade Federal da Bahia.

Na Tabela 5 são reportados os procedimentos metodológicos adotados nos trabalhos analisados sobre evidenciação contábil. 
Tabela 5 - Procedimentos metodológicos adotados nos trabalhos sobre evidenciação contábil socializados no Congresso ANPCONT

\begin{tabular}{l|c|c}
\hline Procedimentos metodológicos & Quant. & Freq. (\%) \\
\hline Análise de conteúdo e uso de ferramentas estatísticas & 38 & 42,23 \\
Análise de conteúdo & 27 & 30,00 \\
Regressão linear múltipla & 8 & 8,89 \\
Regressão logística & 5 & 5,56 \\
Análise sistêmica e de conteúdo & 3 & 3,33 \\
Regressão Tobit e Probit & 2 & 2,22 \\
Teste Shapiro-Wilk, Teste Kolmogorov-Smirnov e Teste Wilcoxon & 2 & 2,22 \\
Teste não paramétrico Kruskall-Wallis & 1 & 1,11 \\
Teste de médias & 1 & 1,11 \\
Análise fatorial & 1 & 1,11 \\
Correlação de Spearman & 1 & 1,11 \\
Método de Monte Carlo & 1 & 1,11 \\
\hline Total & $\mathbf{9 0}$ & $\mathbf{1 0 0}$ \\
\hline
\end{tabular}

Fonte: elaboração própria.

Infere-se da Tabela 5, que parte dos estudos sobre evidenciação contábil socializados no Congresso ANPCONT (42,23\%) fazem uso de análise de conteúdo e de ferramentas estatísticas simultaneamente. A análise de conteúdo é uma técnica que pode ser utilizada para descrever as características de um determinado conjunto de dados (Benin, Diehl, \& Marquezan, 2016). Já as ferramentas estatísticas subsidiam os achados da análise de conteúdo, envolvem o julgamento do pesquisador sobre as informações que devem fazer parte do índice a ser utilizado (Sousa, Silva, Ribeiro, \& Weffort, 2014).

Os resultados reforçam os achados de Carvalho e Ensslin (2006), de Rosa et al. (2009) e de Rosa et al. (2011), visto que a análise de conteúdo foi a técnica mais utilizada entre as pesquisas analisadas. Também os de Manzi e Pimental (2016), que observaram a prevalência nos estudos de evidenciação ambiental do uso de técnicas quantitativas. Portanto, são técnicas que podem ser utilizadas de forma complementar na análise da evidenciação.

O uso exclusivo da análise de conteúdo foi constatado em 27 dos 90 trabalhos analisados (30\%). Segundo Silva e Fossá (2015), esta técnica consiste em uma análise das comunicações investigadas e/ou observadas pelo pesquisador. A análise de conteúdo é usada em trabalhos qualitativos e quantitativos que descrevem e interpretam determinado fenômeno a partir do conteúdo exposto em documentos, no caso da área contábil, pode ser do relatório da administração, notas explicativas, entre outros. Essa metodologia, conduz à uma reinterpretação das mensagens, o que perpassa uma leitura comum (Moraes, 1999).

Métricas estatísticas como a Regressão Linear Múltipla, utilizada por 8 trabalhos, são eficazes para as constatações de relações de comunicação de informações contábeis para os usuários da informação contábil. Hair Jr., Willian, Babin e Anderson (2008, p. 154) asseveram que o propósito desta técnica é "usar variáveis independentes cujos valores são conhecidos para prever os valores da variável dependente selecionada pelo pesquisador".

A Regressão Logística ainda não recebeu tanta atenção por parte dos pesquisadores em algumas áreas do conhecimento (Fávero, 2015). Nos trabalhos analisados, apenas 5 (5,56\%) fizeram uso de tal ferramenta. Segundo Fávero (2015, p. 103), "as técnicas de regressão logística são utilizadas quando o fenômeno a ser estudado apresenta-se de forma qualitativa, e, portanto, representando uma ou mais variáveis dummy, dependendo da quantidade de possibilidades de respostas (categorias) dessa variável dependente". Esta técnica se alinha aos estudos de evidenciação, pois comumente o fenômeno investigado é dicotômico e qualitativo, ou seja, há ou não evidência do fenômeno.

A Análise Sistêmica e de Conteúdo está presente em 3 (3,33\%) dos trabalhos analisados. A importância de se analisar o que está sendo produzido em uma determinada área do conhecimento 
é relevante para a evolução da produção científica e para o aperfeiçoamento das técnicas utilizadas. Também é uma forma de identificar novas oportunidades de pesquisa e suprir uma necessidade, seja acadêmica ou prática. Apesar da pouca atenção atribuída à temática evidenciação, esses estudos apresentam o estado da arte, as características das pesquisas e fragilidades encontradas.

As técnicas de Regressão Tobit e Probit, Teste Shapiro-Wilk, Teste Kolmogorov-Smirnov e Teste Wilcoxon, Teste não paramétrico de Kruskall-Wallis, Teste de Médias, Análise Fatorial, Correlação de Sperman e Método de Monte Carlo representam aproximadamente 10\% das técnicas empregadas nos trabalhos analisados.

Além das técnicas estatísticas mencionadas, diferentes técnicas de pesquisa foram utilizadas. Por exemplo, Lima, Rodrigues e Silva (2010) realizaram um experimento com 456 participantes para analisar se o nível de divulgação de informações de uma entidade pode impactar a percepção de risco dos indivíduos e o processo de avaliação de suas ações. Moreira, Dias Filho, Gomes e Conceição (2012) também inovaram no método de coleta de dados, ao fazerem uso de questionário para identificar fatores que impactam na divulgação voluntária de informações socioambientais na percepção dos gestores.

Essa diversidade de técnicas empregadas nos estudos sobre evidenciação contábil permite inferir que é uma temática em expansão e que a mesma decorre da pluralidade de áreas do conhecimento, como a administração, a contabilidade e a economia (Verrecchia, 2001). Ampliar e aprofundar discussões a partir dessa diversidade é um caminho para aperfeiçoar as práticas e contribuir para avanços teóricos.

A abrangência dos estudos sobre evidenciação contábil é apresentada na Tabela 6, com a investigação de distintos ambientes.

Tabela 6 - Ambiente de abrangência da pesquisa dos trabalhos socializados no Congresso ANPCONT

\begin{tabular}{|c|c|c|}
\hline Ambiente & Quant. & Freq. (\%) \\
\hline Empresas listadas na BM\&FBovespa & 56 & 62,22 \\
\hline Países, União, Estados e Municípios & 9 & 10,00 \\
\hline Empresas listadas na BM\&FBovespa e Bolsas de Valores Internacionais & 5 & 5,56 \\
\hline Periódicos e normas & 4 & 4,44 \\
\hline Fundos de Investimentos, Instituições Financeiras e Outras Entidades & 4 & 4,44 \\
\hline Empresas do Setor Elétrico & 3 & 3,33 \\
\hline Empresas listadas em Bolsas de Valores Estrangeiras & 2 & 2,22 \\
\hline Terceiro Setor & 2 & 2,22 \\
\hline Clubes de Futebol & 2 & 2,22 \\
\hline Companhias de Capital Fechado & 1 & 1,11 \\
\hline Profissionais e discentes do curso de Ciências Contábeis & 1 & 1,11 \\
\hline Empresas do Setor de Ferro e Aço & 1 & 1,11 \\
\hline Total & 90 & 100 \\
\hline
\end{tabular}

Fonte: Dados da pesquisa.

As empresas listadas na BM\&FBovespa, atualmente denominada Brasil Bolsa Balcão (B3), recebem maior interesse por parte dos pesquisadores, sendo o campo de pesquisa de $62,22 \%$ dos trabalhos. A transparência entre países, união, estados e municípios foi o alvo de nove trabalhos. Com escopo de comparar ambientes distintos, identificaram-se cinco trabalhos que investigaram empresas listadas na BM\&FBovespa e em bolsas de valores internacionais simultaneamente, ao passo que dois trabalhos investigaram apenas empresas listadas em bolsas de valores estrangeiras. A verificação da conformidade empresarial foi o foco de quatro trabalhos, que investigaram periódicos e normas. Os fundos de investimentos, instituições financeiras e outras entidades foi o ambiente de investigação de quatro trabalhos.

Por fim, 10 estudos investigaram outros ambientes, como empresas do setor elétrico, terceiro 
setor, clubes de futebol, companhias de capital fechado, profissionais e discentes do curso de Ciências Contábeis e empresas do setor de ferro e aço. A abrangência dos trabalhos alinha-se aos achados de Murcia et al. (2010), em que a fonte secundária de dados teve relevância superior a 50\% em termos de interesse para o campo de pesquisa. Esta é uma característica já esperada, visto que a preocupação central da evidenciação contábil está no usuário externo, ou seja, no que é evidenciado para esses usuários.

No entanto, outros ambientes vêm despertando interesse de pesquisadores, mesmo que em um percentual menor se consideradas as pesquisas que investigaram as empresas listadas na BM\&FBovespa. A evidenciação tornou-se também uma forma de prestação de contas frente aos recursos utilizados e de apresentar aos acionistas as atitudes das empresas. Nesse escopo, as empresas buscam sua própria legitimidade. Vale destacar que a legitimidade é concedida à medida que a sociedade aceita as ações realizadas pelas organizações (Habermas, 1976; Rahaman, Lawrence, \& Roper, 2004).

Outro aspecto relativo a informação investigada é o uso da escala dicotômica, do tipo sim ou não. Nos estudos sobre evidenciação, a substituição de sim e não por um ou zero, um se há presença da informação e zero se há ausência da informação, "é uma das formas amplamente utilizadas nos índices, cujo nível de evidenciação das entidades estudadas costuma ser representado pela soma dos itens de tais escalas" (Suzart, 2016, p. 52). Todavia, a escala dicotômica é uma escala nominal, que segundo Fávero, Belfione, Silva e Chan (2009, p. 29), "representa um nível restritivo de mensuração em termos do uso de técnicas estatísticas, já que não é possível a aplicação de operações aritméticas com seus valores". Na Tabela 7 é mostrado o tipo de informação investigada e o uso da escala dicotômica.

Tabela 7 - Tipos de informações investigadas e uso de escala dicotômica nos trabalhos socializados no Congresso ANPCONT

\begin{tabular}{|c|c|c|c|c|c|c|}
\hline \multirow[b]{2}{*}{ Informações investigadas } & \multirow[b]{2}{*}{ Quant. } & \multirow[b]{2}{*}{$\begin{array}{c}\text { Freq. } \\
(\%)\end{array}$} & \multicolumn{4}{|c|}{ Uso de escala dicotômica } \\
\hline & & & Sim & $\begin{array}{c}\text { Freq. } \\
(\%)\end{array}$ & Não & $\begin{array}{c}\text { Freq. } \\
(\%)\end{array}$ \\
\hline Obrigatória & 40 & 44,44 & 28 & 41,79 & 12 & 52,17 \\
\hline Obrigatória e voluntária & 10 & 11,11 & 9 & 13,43 & 1 & 4,35 \\
\hline Voluntária & 37 & 41,11 & 30 & 44,78 & 7 & 30,43 \\
\hline Involuntária & 1 & 1,11 & 0 & 0,00 & 1 & 4,35 \\
\hline Análise sistêmica e mapeamento do estado da arte & 2 & 2,22 & 0 & 0,00 & 2 & 8,70 \\
\hline Total & 90 & 100,00 & 67 & 100,00 & 23 & 100,00 \\
\hline
\end{tabular}

Fonte: Dados da pesquisa.

Quanto à divulgação obrigatória, 40 trabalhos (44,44\%) investigaram informações desta natureza. Este resultado não coaduna com o argumento de Ayers, Schwab e Utke (2014) de que na temática evidenciação contábil, os estudos que verificam a divulgação obrigatória atraem menos atenção quando comparados a divulgação voluntária. A estrutura legal do Brasil (code-law) pode ser considerada um indutor para a realização de pesquisas com foco em informações obrigatórias.

No Congresso ANPCONT, a divulgação de informações voluntárias foi o foco de $41,11 \%$ dos trabalhos. Esse tipo de divulgação busca mitigar assimetria informacional entre gestores e acionistas, no que concerne ao processo de mudança e continuidade nas empresas. O interesse dos pesquisadores em conhecer o nível de divulgação voluntária das empresas está amparado pela necessidade de prestar contas à sociedade, no que concerne ao seu compromisso social.

Os trabalhos sobre evidenciação contábil que combinaram itens obrigatórios e voluntários representa $11,11 \%$ da amostra. Reconhecer simultaneamente o atendimento das normas e garantir a comunicação e transparência com o mercado é relevante, visto que é uma das formas para reduzir a assimetria informacional, pois em alguns casos a evidenciação é a única forma de comunicação com 
os usuários externos. Alguns fatores culminaram para esse campo de pesquisa, como a harmonização contábil, o aquecimento global, a racionalidade econômica, a aproximação dos mercados e a busca pela sobrevivência em meio a concorrência entre as empresas.

Os trabalhos bibliométricos contribuem para a identificação do estado da arte. Nesse sentido, $2(2,22 \%)$ trabalhos se enquadraram nesta categoria. Por fim, em informações involuntárias identificou-se apenas um trabalho. Quanto à escala dicotômica, a mesma foi identificada em 67 trabalhos $(74,44 \%)$ da amostra pesquisada. Portanto, $74,44 \%$ dos trabalhos averiguaram a presença ou não do fenômeno de interesse e combinaram isso com instrumentos estatísticos. Suzart (2016, p. 25) aduz, quanto a escala dicotômica, que "este tipo de escala é bastante utilizado em pesquisas na área contábil, em razão de permitir um julgamento mais objetivo, visto que a presença ou ausência de um atributo (item) é facilmente verificável".

Na Tabela 8 reportam-se as temáticas sobre evidenciação contábil dos trabalhos socializados no Congresso ANPCONT. Os resultados revelam que a evidenciação ambiental e social de informações contábeis é o campo que mais se destacou, abordado em 34 trabalhos. Atos Regulatórios e Normativos também foram bastante investigados, em 26 trabalhos.

Tabela 8 - Temáticas de evidenciação contábil abordadas nos trabalhos socializados no Congresso ANPCONT

\begin{tabular}{l|c|c}
\hline \multicolumn{1}{c|}{ Temáticas } & \multicolumn{2}{c}{ Trabalhos vinculados } \\
\cline { 2 - 3 } & Quant. & Freq. (\%) \\
\hline Ambiental e Social & 34 & 37,78 \\
Atos Regulatórios e Normativos & 26 & 28,89 \\
Demonstrações Contábeis & 8 & 8,89 \\
Evidenciação de Capital Humano & 4 & 4,44 \\
Informações via Internet & 4 & 4,44 \\
Informação Voluntária & 4 & 4,44 \\
Evidenciação de Guidance & 2 & 2,22 \\
Auditoria & 2 & 2,22 \\
Crise Financeira & 1 & 1,11 \\
Taxa Selic & 1 & 1,11 \\
Escala Dicotômica & 1 & 1,11 \\
Proposta de modelo de cálculo para o nível de disclosure & 1 & 1,11 \\
Indicadores não-financeiros e avaliação de desempenho & 1 & 1,11 \\
Disclosure obrigatório em companhias fechadas & 1 & 1,11 \\
\hline Total & $\mathbf{9 0}$ & $\mathbf{1 0 0}$ \\
\hline
\end{tabular}

Fonte: Dados da pesquisa.

Os resultados demonstrados na Tabela 8 indicam que 37,78\% dos trabalhos de evidenciação contábil socializados no Congresso ANPCONT abordaram a temática ambiental e social, enquanto que 28,89\% investigaram a divulgação de informações relacionadas a atos regulatórios e normativos.

A convergência contábil, prevista na Lei ${ }^{\circ} 11.638$, de 28 de dezembro de 2007, criou um cenário de insegurança no ambiente contábil. Isso despertou interesse dos pesquisadores sobre o que está sendo evidenciado nas demonstrações financeiras, informações sobre capital humano, informações via internet, informação voluntária, entre outros temas. Ferreira e Martins (2016) também identificaram interesse das publicações internacionais nos aspectos relacionados a regulamentação, visto que $42,9 \%$ dos artigos analisados pelos autores sobre evidenciação tinham como foco tal temática.

As teorias de base mais utilizadas nos estudos analisados sobre evidenciação contábil são apresentadas na Tabela 9. Verifica-se que 49\% apresentaram uma teoria de base, enquanto que $51 \%$ não apresentaram ou não fizeram menção à base teórica. 
Tabela 9 - Teorias de base utilizadas nos trabalhos socializados no Congresso ANPCONT

\begin{tabular}{|c|c|c|c|c|c|c|c|c|c|c|c|c|}
\hline \multirow[b]{2}{*}{ Teoria } & \multicolumn{12}{|c|}{ Ano } \\
\hline & 2007 & 2008 & 2009 & 2010 & 2011 & 2012 & 2013 & 2014 & 2015 & 2016 & $\begin{array}{l}\text { To- } \\
\text { tal }\end{array}$ & $\%$ \\
\hline Teoria da Divulgação & 0 & 0 & 2 & 3 & 0 & 3 & 4 & 5 & 3 & 4 & 24 & 38 \\
\hline Teoria da Agência & 0 & 1 & 2 & 0 & 3 & 0 & 1 & 3 & 0 & 1 & 11 & 18 \\
\hline Teoria da Legitimi- & 0 & 1 & 0 & 1 & 0 & 3 & 0 & 2 & 1 & 0 & 8 & 13 \\
\hline Teoria dos Stakeholders & 0 & 1 & 0 & 0 & 2 & 1 & 0 & 0 & 2 & 0 & 6 & 10 \\
\hline $\begin{array}{l}\text { Teoria Institucional } \\
\text { Teoria de Custo do }\end{array}$ & 0 & 1 & 0 & 0 & 0 & 1 & 0 & 1 & 1 & 0 & 4 & 6 \\
\hline Proprietário & 0 & 0 & 0 & 0 & 2 & 0 & 0 & 0 & 0 & 0 & 2 & 3 \\
\hline $\begin{array}{l}\text { Teoria da Economia } \\
\text { Política da Contabili- }\end{array}$ & & & & & & & & & & & & \\
\hline dade & 0 & 1 & 1 & 0 & 0 & 0 & 0 & 0 & 0 & 0 & 2 & 3 \\
\hline Teoria Positiva da & & & & & & & & & & & & \\
\hline Contabilidade & 0 & 0 & 1 & 0 & 0 & 0 & 0 & 1 & 0 & 0 & 2 & 3 \\
\hline Teoria Stewardship & 0 & 0 & 1 & 0 & 0 & 0 & 0 & 0 & 0 & 0 & 1 & 2 \\
\hline Teoria dos Sinais & 0 & 0 & 1 & 0 & 0 & 0 & 0 & 0 & 0 & 0 & 1 & 2 \\
\hline Teoria da Hipótese do & & & & & & & & & & & & \\
\hline Mercado Eficiente & 0 & 0 & 0 & 0 & 0 & 0 & 0 & 1 & 0 & 0 & 1 & 2 \\
\hline Total & & & & & & & & & & & 62 & 100 \\
\hline
\end{tabular}

Fonte: Dados da pesquisa.

Conforme a Tabela 9, a Teoria da Divulgação (38\%) foi a mais utilizada nos trabalhos analisados. Verrecchia (2001) aponta que a divulgação contábil pode ser baseada em: associação, julgamento e eficiência. Pesquisas sobre divulgação baseada em associação, segundo Salotti e Yamamoto (2005, p. 56), "procuram examinar a relação entre o fenômeno da divulgação e as mudanças nas atividades dos investidores diversificados e competidores no mercado de capitais para maximizar as suas riquezas individuais". Divulgação baseada em julgamento é quando "um processo de divulgação passa a ser tratado como um fato endógeno, então as pesquisas questionam os motivos da divulgação ou não de determinada informação" (Salotti \& Yamamoto, 2005, p. 59). Divulgação baseada em eficiência trata da "existência de algumas formas de divulgação que promovem a eficiência" (Salotti \& Yamamoto, 2005, p. 64).

A Teoria da Agência é a segunda base teórica mais utilizada nesses estudos (18\%). Segundo Pinho, Parente e Coelho (2014, p. 03), o disclosure "se apresentou mais relevante para a contabilidade com o surgimento dos conflitos de interesses entre administradores das empresas e seus proprietários, descritos na Teoria da Agência". A evidenciação contábil busca reduzir a "assimetria informacional, e essa redução é relevante não somente nos conflitos de agência, mas também no fluxo de informações nos mercados financeiros" (Pinho, Parente, \& Coelho, 2014, p. 03).

Em oito trabalhos (13\%) foi utilizada a Teoria da Legitimidade. Essa "possui um enfoque sociológico que manifesta a preocupação das empresas em referendar sua atuação na sociedade por meio do cumprimento e respeito aos princípios relativos ao meio ambiente, cidadania, costumes e do ordenamento jurídico de seu entorno" (Conceição, Dourado, \& Silva, 2012, p. 05). Assim, as empresas buscam divulgar o impacto das suas atividades econômicas e sociais, cuja postura foi investigada nos trabalhos.

A Teoria dos Stakeholders foi utilizada em seis trabalhos. O termo stakeholder foi inicialmente empregado em um memorando interno do Stanford Research Institute (SRI), em 1963 (Boaventura, Cardoso, Silva, \& Silva, 2009). A ideia "era designar todos os grupos sem os quais a empresa deixaria de existir. De acordo com este memorando, os grupos de stakeholders incluiriam acionistas, empregados, clientes, fornecedores, credores e a sociedade" (Boaventura et al., 2009, p. 292). As empresas dependem dos stakeholders, por isso devem considera-los na evidenciação contábil. 
Quatro trabalhos utilizaram a Teoria Institucional. Conforme Silva, Rech e Cunha (2014, p. 03), "a Teoria Institucional surge com o intuito de explicar o fenômeno de as organizações seguirem estruturas formais ou institucionalizadas". Para Wood e Caldas (2007, p. 184), “a institucionalização diz respeito a uma série de processos sociais pelos quais construções socialmente legitimadas, a respeito de práticas ou comportamentos de entidades individuais (por exemplo, organizações), adquirem um status normativo na ação social".

A Teoria de Custo do Proprietário foi utilizada em dois trabalhos. "Segundo essa Teoria, quanto maior a extensão da evidenciação de informações empresariais, maiores poderão ser os custos do proprietário" (Jacques \& Macagnan, 2011, p. 07). Como exemplo, tem-se o trabalho de Jacques e Macagnan (2011), que analisou se a extensão da evidenciação de informações nos pareceres de auditoria está relacionada com a variação do valor médio das ações das companhias abertas listadas na BM\&FBovespa.

A Teoria da Economia Política da Contabilidade foi utilizada em dois trabalhos. Ela focalizase na relação entre economia, mercado e estado. Ao contrário da economia neoclássica, "que enfatiza as relações individuais, assumindo premissas de racionalidade humana, isenta de valores, a Economia Política estuda a relação da economia dentro de um amplo espectro político e engajada em um ambiente social valorativo" (Nascimento, Santos, Salotti, \& Múrcia, 2008, p. 03). Os dois trabalhos que fizeram uso desta Teoria utilizaram-na para investigar a evidenciação de informações contábeis.

A Teoria Positiva da Contabilidade foi utilizada em dois trabalhos. Rover, Tomazzia, Murcia e Borba (2009, p. 03) expõem que "a formulação desta Teoria, parte do princípio de que os gestores das empresas maximizam a sua utilidade, e que esta utilidade é função positiva das compensações futuras (ou seja, riqueza) e uma função negativa da dispersão desta compensação". Advertem ainda que, "os gestores têm grandes incentivos em adotar padrões contábeis que resultem em maior valor das ações que possuem (maior fluxo de caixa) ou maiores bônus de desempenho (maiores taxas de lucro)".

A Teoria do Representante (Stewardship) foi utilizada em um trabalho. Segundo Martins e Rodrigues (2005, p. 23), ela "contrapõe diretamente os argumentos de oportunismo dos gestores (agentes) propostos pela Teoria da Agência. Sob esta ótica, os gestores são motivados por outras razões que não exclusivamente a financeira e, por isso, representam bem os interesses da empresa". Conforme Martins e Rodrigues (2005, p. 23), os gestores são motivados também para "alcançar e ganhar satisfação intrínseca com a execução de trabalho desafiador, exercer autoridade e responsabilidade, obtendo o reconhecimento do chefe".

Em um trabalho foi utilizada a Teoria dos Sinais (Signals Theory), a qual determina que as práticas de divulgação voluntária são destinadas a informar os acionistas e o mercado de capitais. A divulgação voluntária de itens são sinais dirigidos aos investidores com o propósito de reduzir a assimetria de informações entre os insiders e outsiders. Segundo Mussa, Yang, Trovão e Famá (2008, p. 5), a base da Hipótese da Eficiência de Mercado (HEM) é que "o preço de um ativo reflete as informações disponíveis sobre a instituição emissora, impossibilitando aos investidores qualquer ganho anormal".

Depreende-se do exposto que, na temática investigada, existe uma multidisciplinaridade de teorias de suporte, o que contribui para a evolução do conhecimento. Na Tabela 10 apresentam-se as teorias adotadas e as respectivas áreas temáticas investigadas. Reforça-se os achados anteriores no que concerne ao volume de pesquisas que têm como abordagem a evidenciação obrigatória e as teorias utilizadas para sustentar as temáticas investigadas. É possível ainda perceber lacunas de pesquisas e o escopo da literatura. 
Tabela 10 - Teorias adotadas por área temática e por tipo de informação investigada nos trabalhos socializados no Con-

\begin{tabular}{|c|c|c|c|}
\hline $\begin{array}{l}\text { Tipo de evi- } \\
\text { denciação }\end{array}$ & Teorias & Temáticas & Quant. \\
\hline \multirow{7}{*}{ Obrigatória } & Teoria da Divulgação & $\begin{array}{l}\text { Atos Regulatórios e Normativos } \\
\text { IFRS } \\
\text { Informações via Internet } \\
\text { Demonstrações Contábeis } \\
\text { Disclosure Obrigatório em Companhias Fe- } \\
\text { chadas }\end{array}$ & $\begin{array}{l}4 \\
1 \\
1 \\
2 \\
1\end{array}$ \\
\hline & Teoria da Agência & $\begin{array}{l}\text { Auditoria } \\
\text { Atos Regulatórios e Normativos }\end{array}$ & $\begin{array}{l}2 \\
2 \\
\end{array}$ \\
\hline & Teoria dos Stakeholders & $\begin{array}{l}\text { Atos Regulatórios e Normativos } \\
\text { Ambiental e Social }\end{array}$ & $\begin{array}{l}1 \\
1\end{array}$ \\
\hline & Teoria Institucional & Atos Regulatórios e Normativos & 1 \\
\hline & Teoria de Custo do Proprietário & Auditoria & 1 \\
\hline & Hipótese do Mercado Eficiente & Atos Regulatórios e Normativos & \\
\hline & Teoria Positiva da Contabilidade & Atos Regulatórios e Normativos & 1 \\
\hline \multirow{10}{*}{ Voluntária } & Teoria da Divulgação & $\begin{array}{l}\text { Ambiental e Social } \\
\text { Informação Voluntária } \\
\text { Informações via Internet } \\
\text { Demonstrações Contábeis } \\
\text { Evidenciação de Guidance }\end{array}$ & $\begin{array}{l}7 \\
1 \\
1 \\
1 \\
1\end{array}$ \\
\hline & Teoria da Legitimidade & $\begin{array}{l}\text { Ambiental e Social } \\
\text { Evidenciação de Capital Humano }\end{array}$ & $\begin{array}{l}6 \\
1 \\
\end{array}$ \\
\hline & Teoria da Agência & $\begin{array}{l}\text { Ambiental e Social } \\
\text { Informações via Internet } \\
\text { Evidenciação de Capital Humano }\end{array}$ & $\begin{array}{l}3 \\
1 \\
1\end{array}$ \\
\hline & Teoria dos Stakeholders & Ambiental e Social & 4 \\
\hline & Teoria Institucional & Ambiental e Social & 2 \\
\hline & $\begin{array}{l}\text { Teoria da Economia Política da Con- } \\
\text { tabilidade }\end{array}$ & Ambiental e Social & 2 \\
\hline & Teoria de Custo do Proprietário & Evidenciação de Capital Humano & 1 \\
\hline & Teoria Stewardship & Ambiental e Social & 1 \\
\hline & Teoria de Sinais & Ambiental e Social & 1 \\
\hline & Teoria Positiva da Contabilidade & Ambiental e Social & 1 \\
\hline \multirow{4}{*}{$\begin{array}{l}\text { Obrigatória e } \\
\text { Voluntária }\end{array}$} & Teoria da Divulgação & $\begin{array}{l}\text { Demonstrações Contábeis } \\
\text { Escala Dicotômica } \\
\text { Ambiental e Social }\end{array}$ & $\begin{array}{l}2 \\
1 \\
1\end{array}$ \\
\hline & Teoria da Agência & Demonstrações Contábeis & 2 \\
\hline & Teoria Institucional & Atos Regulatórios e Normativos & 1 \\
\hline & Teoria da Legitimidade & Ambiental e Social & 1 \\
\hline
\end{tabular}

Fonte: Dados da pesquisa.

As teorias da Divulgação, da Agência e Institucional subsidiaram estudos sobre evidenciação contábil envolvendo informações obrigatórias, voluntárias e ambas conjuntamente. A Teoria dos Stakeholders está presente em estudos sobre informações obrigatórias e voluntárias. As teorias de Custo do Proprietário, Positiva da Contabilidade e da Hipótese do Mercado Eficiente foram utilizadas somente em estudos que investigaram informações obrigatórias. Nos estudos sobre divulgação de informações obrigatórias, as temáticas dominantes relacionam-se com atos normativos e regulatórios, em especial a Lei $n^{\circ}$ 6.404/76, que define "um conjunto mínimo de informações que devem ser disponibilizadas pelas organizações de capital aberto" (Ponte, Oliveira, Moura, \& Carmo, 2007, p. 53).

A Teoria da Legitimidade está presente em estudos sobre evidenciação voluntária e de forma 
conjunta com a divulgação obrigatória. Já as teorias da Economia Política da Contabilidade, do Disclosure Discricionário, Stewardship e de Sinais consubstanciaram somente estudos sobre divulgação voluntária. As temáticas dominantes neste escopo foram a divulgação de informação ambiental e social e aspectos relacionados ao fator humano.

Com base nos elementos bibliométricos analisados, os resultados desta pesquisa convergem com os estudos de Carvalho e Ensslin (2006), Rosa et al. (2009), Murcia et al. (2010), Rosa et al. (2011), Ferreira e Martins (2016) e Manzi e Pimentel (2016). Esses autores, realizaram estudos bibliométricos que mapearam o campo de pesquisa na área de evidenciação. Os resultados instigam que futuras pesquisas combinem elementos teóricos, temáticos e de evidenciação, de modo a convergir com uma estrutura metodológica já difundida na literatura.

\section{CONCLUSÕES}

Nos trabalhos sobre evidenciação contábil socializados no Congresso ANPCONT, no período de 2007 a 2016, observou-se que há diferentes áreas temáticas envolvidas na evidenciação contábil. Nesses trabalhos, a evidenciação contábil recebeu maior atenção a partir de 2009, período de convergência às normas internacionais, quando a preocupação com a transparência e com a qualidade da informação contábil gerada ganhou mais atenção. Quanto ao vínculo institucional dos autores, os resultados estão alinhados com o estabelecido na Lei de Lotka. Destaca-se em especial que duas instituições apresentaram predominância de autoria nos trabalhos (UFC e USP), com 10\% de autoria dos trabalhos.

As teorias mais usadas no suporte à temática evidenciação contábil foram: Teoria da Divulgação, Teoria da Agência, Teoria da Legitimidade, Teoria dos Stakeholders, Teoria Institucional e Teoria da Economia Política da Contabilidade. Essas também foram observadas no estudo de Nascimento et al. (2008). Na pesquisa observou-se uma multidisciplinaridade temática, pois diferentes teorias foram utilizadas para explicar os determinantes da evidenciação voluntária e obrigatória.

No que concerne à metodologia adotada nos trabalhos analisados, a análise de conteúdo combinada com o uso de ferramentas estatísticas foram as técnicas mais utilizadas. No entanto, o uso da escala dicotômica também foi observado, sendo que os pesquisadores devem ter cuidado ao fazer uso de tal escala para a construção de índices de evidenciação, uma vez que este pode ser distorcido, conforme destacado por Suzart (2016).

As evidências destacadas na análise dos trabalhos revelam a evolução da temática ao longo do tempo no Congresso ANPCONT. Por exemplo, no período de 2007 a 2009, dos 12 trabalhos analisados, todos tiveram como premissa básica a verificação da divulgação de informações ambientais e sociais. Já no período de 2014 a 2016, dos 38 analisados, apenas 8 tiveram como foco tal aspecto. Esses resultados denotam que o foco da evidenciação incluiu outras áreas de preocupações corporativas, como a divulgação de contingências tributárias, ativos intangíveis, instrumentos financeiros, entre outros.

O estudo realizado também indica algumas fragilidades no desenvolvimento de pesquisas sobre evidenciação contábil, como a forte influência de órgãos normatizadores na condução das pesquisas, com ênfase na evidenciação compulsória. O desafio para futuras pesquisas é o desenvolvimento de metodologias que englobem a complexidade do processo de evidenciação da informação contábil.

Este estudo apresenta como uma das limitações o foco em um único evento científico, portanto, os resultados impedem sua expansão para outros eventos da área contábil. A metodologia adotada se apresenta como outra limitação, dado a fragilidade de uma busca sistemática, por exemplo, as escolhas das categorias e a ambiguidade dos termos escolhidos. Os aspectos caracterizados como limitações desta pesquisa podem servir de inspiração para futuras pesquisas sobre evidenciação contábil. 


\section{REFERÊNCIAS}

Amaral, M.R., Santana, C.M., Sales, I.C.H., \& Araujo Neto, L.M. (2014). Perfil dos autores na produção científica em mercado financeiro de crédito e de capitais nos Congressos USP de Controladoria e Contabilidade e Congresso ANPCONT. Revista Evidenciação Contábil E Finanças, 2(2), 5568 .

Araújo, V.R.B.S., Machado, M.R., \& Machado, M.A.V. (2016). Disclosure voluntário e liquidez acionária. Anais do Congresso ANPCONT, Ribeirão Preto, SP, Brasil, 10.

Ayers, B.C., Schwab, C.M., \& Utke, S. (2014). Noncompliance with mandatory disclosure requirements: The magnitude and determinants of undisclosed permanently reinvested earnings. The Accounting Review, 90(1), 59-93.

Barboza, M.M.B.M., Sousa, W.D., Nascimento, J.C.H.B., Bernardes, J.R., \& Castro, M.B.M.B. (2015). O perfil da pesquisa bibliométrica publicada nas 19 edições do Congresso Brasileiro de Custos. ABCustos, 10(2), 87-117.

Belo, N.M., \& Brasil, H.G. (2006). Assimetria informacional e eficiência semiforte do mercado. Revista de Administração de Empresas, 46(SPE), 48-57.

Benin, M.M., Diehl, C.A., \& Marquezan, L.H.F. (2016). A evidenciação de indicadores não financeiros de medição de desempenho por clubes de futebol brasileiros. Anais do Congresso ANPCONT, Ribeirão Preto, SP, Brasil, 10.

Bernd, D.C., Anzilago, M., \& Beuren, I.M. (2017). Presença do gênero feminino entre os discentes dos Programas de Pós-Graduação de Ciências Contábeis no Brasil. Revista de Educação e Pesquisa em Contabilidade (REPeC), 11(4), 408-429.

Boaventura, J.M.G., Cardoso, F.R., Silva, E.S., \& Silva, R.S. (2009). Teoria dos Stakeholders e Teoria da Firma: um estudo sobre a hierarquização das funções-objetivo em empresas brasileiras. Revista Brasileira de Gestão de Negócios, 11(32), 289-307.

Cardoso, R.L., Pereira, C.A., \& Guerreiro, R. (2007). Perfil das pesquisas em contabilidade de custos apresentadas no EnANPAD no período de 1998 a 2003. Revista de Administração Contemporânea, 11(3), 177-198.

Carvalho, F.N., \& Ensslin, S.R. (2006). A evidenciação voluntária do capital intelectual: um estudo revisionista do contexto internacional. Contabilidade Vista \& Revista, 17(4), 55-72.

Comitê de Pronunciamentos Contábeis. Pronunciamento Conceitual Básico CPC 00 (R1). Estrutura Conceitual para Elaboração e Divulgação de Relatório Contábil-Financeiro. 2011.

Conceição, S.H., Dourado, G.B., \& Silva, S.F. (2012). Global Reporting Initiative (GRI): Um estudo exploratório da prática de evidenciação em sustentabilidade empresarial na América Latina. Anais do Congresso ANPCONT, Florianópolis, SC, Brasil, 6.

Cosenza, J.P., Paula, M.M., Laurencel, L.C., \& Barreto, P.S. (2016). Análise das características e similaridades presentes na produção científica dos Congressos ANPCONT 2007-2014. Revista Contemporânea de Contabilidade, 13(28), 0-0.

Dallabona, L.F., Utzig, M.J.S., Moura, G.D., Zonatto, V., \& Ribeiro, M.J. (2011). Retrospectiva dos quatro anos de ANPCONT: Análise dos aspectos metodológicos e perfil dos congressistas. Advances in Scientific and Applied Accounting, 4(3), 406-432. 
Fama, E.F. (1970). Efficient capital markets: a review of theory and empirical work. Journal of Finance, 25(2), 383-417.

Fávero, L.P. (2015). Análise de dados: modelos de regressão com Excel, Stata e SPSS. Rio de Janeiro: Elsevier.

Fávero, L.P., Belfione, P., Silva, F.L., \& Chan, B.L. (2009). Análise de dados: modelagem multivariada para a tomada de decisões. Rio de Janeiro: Elsevier.

Formiga, M.V., Barros, C.M.E., Cezário, N.J., \& Scherer, L.M. (2017). O efeito da incerteza política no desempenho e valoração das companhias abertas brasileiras. Anais do Congresso ANPCONT, Belo Horizonte, MG, Brasil, 11.

Gibbins, M., Richardson, A., \& Waterhouse, J. (1990). The management of corporate financial disclosure: opportunism, ritualism, policies, and processes. Journal of Accounting Research, 28(1),121143

Guedes, T.A., Martins, A.B.T., Acorsi, C.R.L., \& Janeiro, V. (2015). Estatística descritiva. Projeto de Ensino. Recuperado em 04 julho, 2016, de http://www.uspleste.usp.br/rvicente/Estatistica_Descritiva.pdf

Habermas J. (1976). Legitimation crisis. London: Heinemann.

Hair Jr., J.F., William, B., Babin, B., \& Anderson, R.E. (2009). Análise multivariada de dados. 6. ed. Porto Alegre: Bookman.

Hendriksen, E.S., \& Van Breda, M.F. (1999). Teoria da contabilidade. São Paulo: Atlas.

Iudícibus, S. (2000). Teoria da contabilidade (6. ed.). São Paulo: Atlas.

Jacques, F.V.S., \& Macagnan, C.B. (2011). A relação entre a evidenciação de informações nos pareceres de auditoria e o valor das ações de companhias abertas listadas na Bovespa Anais do Congresso ANPCONT, Vitória, ES, Brasil, 5.

Lanzana, A.P. (2004). Relação entre disclosure e governança corporativa das empresas brasileiras. Tese de Doutorado, Universidade de São Paulo, São Paulo, SP, Brasil.

Lei n⿳o 6.404, de 15 de dezembro de 1976 (1976). Dispõe sobre as Sociedades por Ações. Recuperado em 29 fevereiro, 2016, de http://www.planalto.gov.br/ccivil_03/leis/L6404compilada.htm

Lima, D.H.S., Rodrigues, J.M., \& Silva, C.A.T. (2010). Impacto do nível de evidenciação de informações contábeis sobre a precificação de ações no contexto de seleção adversa. Anais do Congresso ANPCONT, Natal, RN, Brasil, 4.

Lima, G.H., Costa, K., Pinheiro, L.E.T., \& Lamounier, W.M. (2016). Fatores determinantes do nível de divulgação sobre partes relacionadas: Estudo nas companhias listadas no IBrX100. Anais do Congresso ANPCONT, Ribeirão Preto, SP, Brasil, 10.

Luca, M.M.M., Gomes, C.A.S., Corrêa, D.M.M.C., \& Domingos, S.R.M. (2011). Participação feminina na produção científica em contabilidade publicada nos anais dos dos Eventos Enanpad, Congresso USP de Controladoria e Contabilidade e Congresso ANPCONT. Revista de Contabilidade e Organizações, 5(11), 145-164.

Macedo, A.F.P., Oliveira, A.M., Nobre, L.N., Brito, S.G., \& Quandt, C.O. (2015). Governança corporativa e evidenciação de capital intelectual em empresas brasileiras. Revista Evidenciação Contábil E Finanças, 3(1), 18-33. 
Macedo, M.A.D.S., Almeida, J.E.F.D., \& Dornelles, O.M. (2017). Os mercados acionários internacionais reagem mais às demonstrações contábeis ou às notícias? O caso do escândalo do Banco HSBC. Pensar Contábil, 18(67), 5-22.

Maciel, G.F.D.S.V., Wolff, M.G.C, \& Rêgo, R.B. (2016). Teste de eficiência de mercado no Brasil: Um estudo de caso na Petrobras. Relatórios de Pesquisa em Engenharia de Produção, 15(1), 1-7.

Manzi, S.M.S., \& Pimentel, M.S. (2016). Produção científica sobre disclousure ambiental: um levantamento a partir de artigos publicados em periódicos nacionais no período de 2005 a 2015. Custos e @gronegócio, 12(Esp), 170-190.

Martins, H.C., \& Rodrigues, S.B. (2005). Atributos e papéis dos conselhos de administração das empresas brasileiras. Revista de Administração de Empresas, 45(SPE), 23-35.

Matos, E.B.S., Niyama, J.K., Araujo Neto, L.M., \& Marques, M.M. (2012). Congresso ANPCONT: análise bibliométrica descritiva e avaliativa dos artigos publicados de 2007 a 2011. Enfoque Reflexão Contábil, 31(3), 73-88.

Mattos, P.L.C.L. (2004). "Bibliometria": a metodologia acadêmica convencional em questão. RAE-eletrônica, 3(2), 1-6.

Mendes, M.G. (2013). Efeitos do disclosure involuntário negativo decorrente de acidentes ambientais na volatilidade das ações. Anais do Congresso ANPCONT, Fortaleza, CE, Brasil, 7.

Moraes, R. (1999). Análise de conteúdo. Revista Educação, 22(37), 7-32.

Moreira, N.B., Dias Filho, J.M., Gomes, S.M.S., \& Conceição, M.G. (2012). Fatores que impactam a divulgação voluntária de informações socioambientais na percepção dos gestores de empresas brasileiras de energia elétrica. Anais do Congresso ANPCONT, Florianópolis, SC, Brasil, 6.

Murcia, F.D.R., Santos, A., Salotti, B.M., \& Nascimento, A. (2010). Mapeamento da pesquisa sobre disclosure ambiental no cenário internacional: uma revisão dos artigos publicados em periódicos de língua inglesa no período de 1997 a 2007. ConTexto, 10(17), 7-18.

Mussa, A., Yang, E., Trovão, R., \& Famá, R. (2008). Hipótese de mercados eficientes e finanças comportamentais: as discussões persistem. FACEF Pesquisa-Desenvolvimento e Gestão, 11(1), 5-17.

Nascimento, A.R., Santos, A., Salotti, B., \& Múrcia, F.D.-R. (2008). Disclosure social e ambiental: a produção científica veiculada em periódicos de língua inglesa entre 1997 e 2007. Anais do Congresso ANPCONT, Salvador, BA, Brasil, 2.

Paula, L.F.D., \& Pires, M. (2017). Crise e perspectivas para a economia brasileira. Estudos Avançados, 31(89), 125-144.

Paula, M.M., Silva, A.J.S., Vieira, J., \& Coutinho, A. (2012). Diálogo científico nos congressos ANPCONT: diversidade inovadora ou isomorfismo institucionalizado? Contabilidade, Gestão e Governança, 15(3), 35-51.

Paula, M.M., Silva, A.J.S., Vieira, J., \& Coutinho, A. (2012). Perfil da pesquisa nos Congressos Anpcont: Diversidade inovadora ou isomorfismo institucionalizado? Anais do Congresso ANPCONT, Vitória, ES, Brasil, 5.

Pinho, G.A., Parente, P.H.N., \& Coelho, A.C.D. (2014). Associação entre risco e evidenciação de instrumentos financeiros no Brasil. Anais do Congresso ANPCONT, Rio de Janeiro, RJ, Brasil, 8.

Ponte, V.M.R., Oliveira, M.C., Moura, H., \& Carmo, R.C.D.A. (2007). Análise das práticas de evidenciação de informações obrigatórias, não-obrigatórias e avançadas nas demonstrações contábeis 
das sociedades anônimas no Brasil: um estudo comparativo dos exercícios de 2002 e 2005 . Revista Contabilidade $\mathcal{E}$ Finanças, 18(45), 50-62.

Rahaman, A.S., Lawrence, S., \& Roper, J. (2004). Social and environmental reporting at the VRA: institutionalised legitimacy or legitimation crisis? Critical Perspectives on Accounting, 15(1), 3556.

Ribeiro, H.C.M. (2017). Produção acadêmica da área temática Mercados Financeiro, de Crédito e de Capitais (MFC) divulgada no ANPCONT de 2007 a 2016. Revista Evidenciação Contábil \& Finanças, 5(3), 79-98.

Ribeiro, R.R.M., Camacho, R.R., Moraes, R.O., \& Raimundini, S.L. (2015). Contabilidade gerencial: análise da cientificidade e da metodologia dos artigos publicados no EnANPAD e ANPCONT. Revista Capital Científico - Eletrônica, 13(1), 26-40.

Rosa, F.S., Ensslin, S.R., \& Ensslin, L. (2009). Evidenciação ambiental: processo estruturado de revisão de literatura sobre avaliação de desempenho da evidenciação ambiental. Sociedade, Contabilidade e Gestão, 4(2), 24-37.

Rosa, F.S., Ensslin, S.R., Ensslin, L., \& Lunkes, R.J. (2011). Gestão da evidenciação ambiental: um estudo sobre as potencialidades e oportunidades do tema. Engenharia Sanitária Ambiental, 16(1), 157-166.

Rover, S., Tomazzia, E.C., Murcia, F.D.-R., \& Borba, J.A. (2009). Explicações para a divulgação voluntária ambiental no Brasil utilizando análise de regressão em painel. Anais do Congresso ANPCONT, São Paulo, SP, Brasil, 3.

Salotti, B.M., \& Yamamoto, M.M. (2005). Ensaio sobre a teoria da divulgação. BBR-Brazilian Business Review, 2(1), 53-70.

Santos, M.A., Pires, E.G., Macambira, M.O., \& Bruni, A.L. (2013). A construção do conhecimento sobre ensino e aprendizagem em contabilidade: um olhar sobre os Congressos USP e ANPCONT no período de 2007 a 2011. Revista Evidenciação Contábil \& Finanças, 1(1), 71-84.

Silva, A.H., \& Fossá, M.I.T. (2015). Análise de conteúdo: Exemplo de aplicação da técnica para análise de dados qualitativos. Qualitas Revista Eletrônica, 16(1), 1-14.

Silva, M.A., Rech, I.J., \& Cunha, M.F. (2014). Influência do isomorfismo organizacional no nível de evidenciação de ativos intangíveis. Anais do Congresso ANPCONT, Rio de Janeiro, RJ, Brasil, 8.

Skillius, A., \& Wennberg, U. (1998). Continuity, credibility and comparability: key challenges for corporate environmental performance measurement and communication. Intenational Institute for Industrial Environmental Economics, Lund University.

Sousa, C.B., Silva, A.F., Ribeiro, M.S., \& Weffort, E.F.J. Valor de mercado e disclosure voluntário: estudo empírico em companhias listadas na BM\&FBOVESPA. Revista Ambiente Contábil, 6(2), 94-155.

Suzart, J.A.S. (2016). Índices de evidenciação: quando um mais zero não é igual a um. Contabilometria, $3(1), 52-70$.

Van Der Stede, W.A. (2015). Management accounting: Where from, where now, where to? Journal of Management Accounting Research, 27(1), 171-176.

Vanti, N.A.P. (2002). Da bibliometria à webometria: uma exploração conceitual dos mecanismos utilizados para medir o registro da informação e a difusão do conhecimento. Ciência da Informação, $31(2), 152-162$. 
Verrecchia, R.E. (2001). Essays on disclosure. Journal of Accounting and Economics, 32(1), 97-180.

Wood Jr, T., \& Caldas, M.P. (2007). Comportamento organizacional: uma perspectiva brasileira (2. ed.). São Paulo: Atlas. 